\title{
Ektrodaktili Ektodermal Displazi-Klefting Sendromlu Ailesel Üç Olgu
}

\section{Three Familial Cases with Ectrodactyly Ectodermal Displazia-Clefting Syndrome}

\section{Selma Bakar Dertlioğlu, Demet Çiçek*, Illyas Özardalı**}

Harran Üniversitesi Tıp Fakültesi, Dermatoloji Anabilim Dalı ve **Patoloji Anabilim Dalı, Șanlıurfa, Türkiye

*Fırat Üniversitesi Tıp Fakültesi Deri ve Zührevi Hastalıklar Anabilim Dalı, Elazığ, Türkiye

\section{Özet}

Anne-baba arasında akraba evliliği öyküsü olan dört çocuklu bir aile 10 yaș, altı yaș ve üç aylık kız çocuklarında saçlarda uzamama, tüm vücut kıllarında seyrelme ve parmaklarda șekil bozukluğu șikayeti ile polikliniğimize bașvurdu. Hastaların dermatolojik muayenesinde saçlar, kașlar ve ekstremitelerde kıllarda seyrelme, tırnaklarda subungual hiperkeratoz, palmoplantar hiperkeratoz, deride yaygın terleme kaybı ve kuruluk, dișlerde konik görünüm ve hipodonti saptandı. Her üç kardeșin de ellerinde 3-4. parmaklarda, ayaklarında 2-3-4. parmaklarda proksimalde yapıșıklık gözlendi. Hastalardan alınan deri biyopsi materyallerinin histopatolojik incelenmesinde kıl folikülleri ve sebase glandlarda sayıca azalma ve boyutlarda küçülme saptandı. Klinik ve histopatolojik değerlendirme sonucunda Ektrodaktili ektodermal displazi-klefting sendromu tanısı konulan bu ailesel olguları nadir gözlenmesi nedeniyle sunuyoruz. (Türkderm 2012; 46: 47-9)

Anahtar Kelimeler: Ektrodaktili ektodermal displazi-klefting sendromu, ektodermal displazi-kutanöz sindaktili sendromu, ektodermal displazi

\section{Summary}

A family of four children where mother and father had history of consanguineous marriage presented at our clinic due to lack of hair growth, thinning of all body hair and finger deformities in their three daughters aged 10 years, six years and three months. Dermatological examination of the cases showed thinning of the hair on the scalp, eyebrows, and extremities, subungual hyperkeratosis in nails, palmoplantar hyperkeratosis, cutaneous xerosis and loss of sweating, conical appearance and hypodontia in the teeth. All three siblings were seen to have the 3rd and 4th digits on the hand and the 2nd, 3rd and 4th digits on the feet to be proximally conjoined. Histopathologic examination of the cutaneous biopsy materials taken from the patients revealed a decrease in the number and size of hair follicles and sebaceous glands. We present these familial cases who were diagnosed with Ectrodactyly-ectodermal dysplasia-clefting syndrome as a result of clinical and histopathologic evaluation due to their rarity. (Turkderm 2012; 46: 47-9)

Key Words: Ectrodactyly-ectodermal dysplasia-clefting syndrome, Ectodermal dysplasia-cutaneous syndactyly syndrome, ectodermal dysplasia

\section{Giriş}

Ektodermal displazi (ED) saç, diş, kaş, kirpik, tırnak, yağ ve ter bezleri gibi ektodermden köken alan doku ve organları etkileyen kalıtsal bir hastalık grubudur. Hastalığın farklı klinik bulgulardan oluşan alt tipleri mevcuttur. Sıklıkla $X$ resesif, nadiren otozomal resesif veya otozomal dominant geçişli olabilir. Etkilenen hastaların \%90'ı erkektir ${ }^{1-6 .}$
Hastalığın etki derecesi birtakım genetik değişikliklerin geçiş farklılıklarına bağlıdır. Freire-Maia ektodermal bozuklukları 4 ana grupta incelemiştir5,6:

1. Hipohidroz: Yağ ve ter bezlerinin olmaması veya az olması

2. Hipotrikoz: Ince ve seyrek saçlar, kaş ve kirpiklerin yokluğu

3. Hipodonti: Anodonti veya daha sıklıkla oligodonti

4. Onikodisplazi: Displazik tırnak

Yazışma Adresi/Address for Correspondence: Dr. Demet C̦içek, Firat Üniversitesi Tip Fakültesi, Dermatoloji Anabilim Dall, Elazı̆̆, Türkiye Tel.: +90 42423335 55/2009 E-posta: dr.demetcicek@hotmail.com Geliş Tarihi/Received: 09.10.2010 Kabul Tarihi/Accepted: 15.12.2010

Türkderm-Deri Hastalıkları ve Frengi Arșivi Dergisi, Galenos Yayınevi tarafından basılmıștır. Turkderm-Archives of the Turkish Dermatology and Venerology, published by Galenos Publishing. 


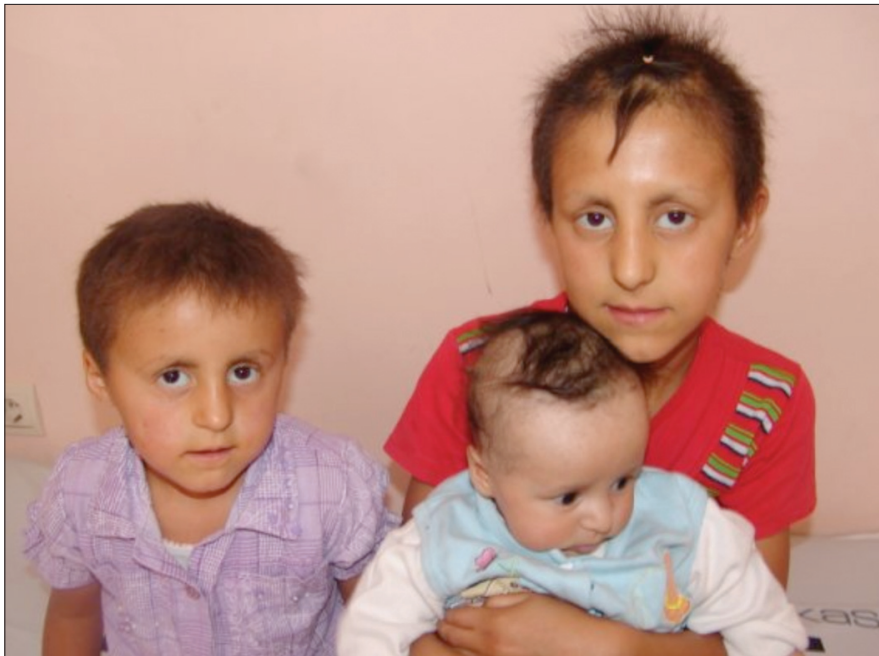

Resim 1. Üç kız kardeşte (10 yaş, altı yaş ve 3 aylık) ciltte kuruluk, saçlar, kaşlar ve kirpiklerde seyrelme, sivri burun, burun kökünde basıklık, ince üst dudak ve geniş kulak kepçesi şeklinde atipik yüz görünümleri

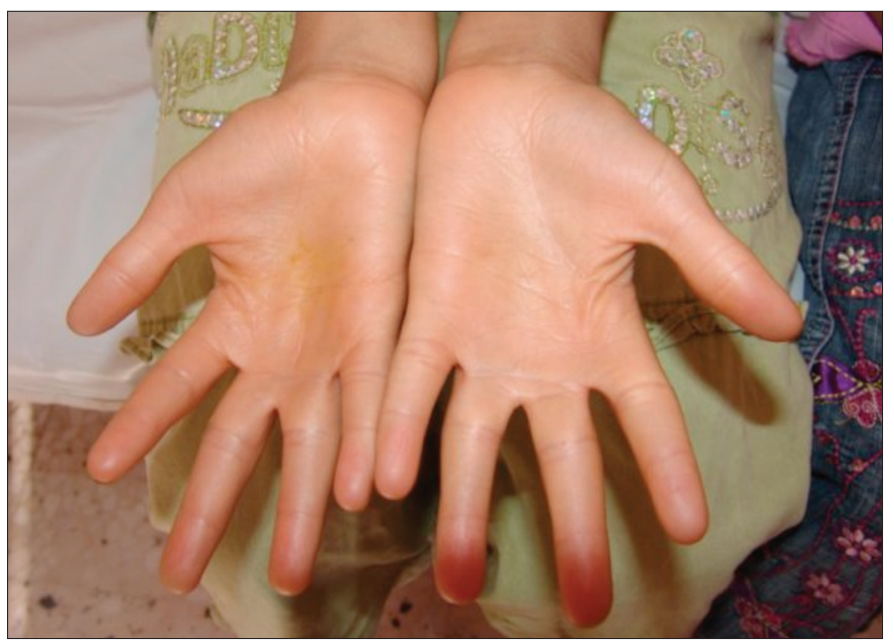

Resim 2. Bilateral ellerde 3-4. parmaklarda proksimalde yapışıklık, geniş avuç içi ve kısa parmaklar

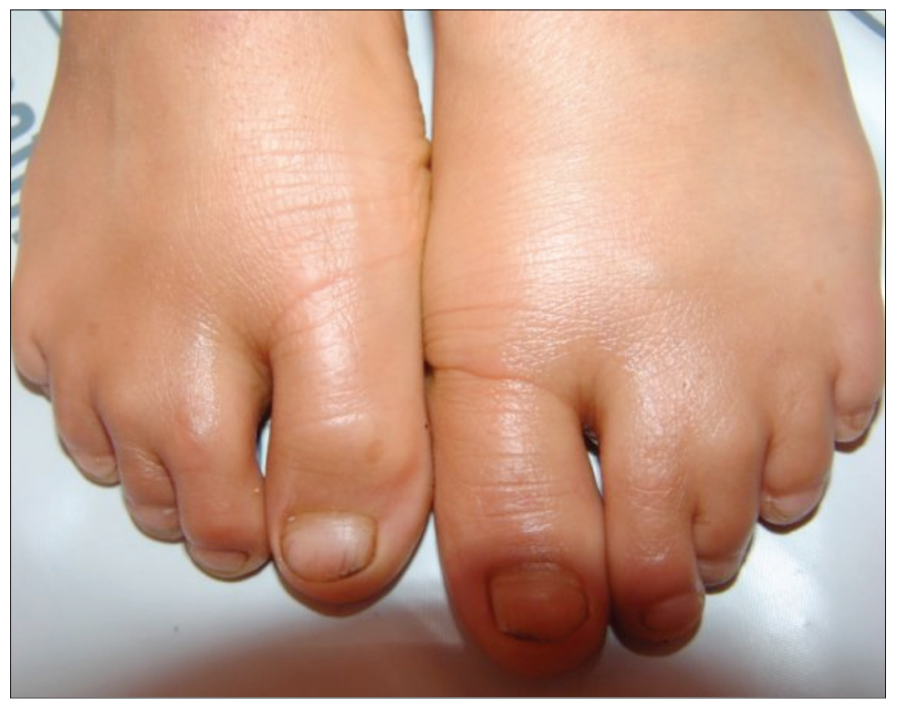

Resim 3. Bilateral ayaklarda 2-3-4. parmaklarda proksimalde yapışıklık
Tanı için konjenital, diffüz, ilerleyici olmayan ve en az bir ektodermal eki içine alan hastalık olması gereklidir 1,4,6.

Bu makalede ED tanısı konulan üç kardeş incelenerek, seyrek olarak görülen sendromun kutanöz sindaktili ile birlikteliği sunulmuştur.

\section{Olgular}

Dört çocuklu bir ailenin 10 yaş, altı yaş ve üç aylık olan kız çocukları doğumdan itibaren saçların seyrek olması, zor uzaması, kolay dökülmesi, dişlerin geç çıkması ve dişlerde şekil bozukluğu şikayetleri ile polikliniğimize başvurdu. Kız çocuklarından bir tanesi dışında diğer üç çocukta benzer şikayetler mevcut olan anne ve baba 2 . dereceden akraba idi. Anne-baba sağlıklı olup, ailede benzer şikayetleri olan hiç kimse yoktu.

Sistemik muayenede çocukların ağırlık, boy ve baş çevresi ölçümleri normal olarak tespit edildi. Her üç çocukta da deri ince ve kuru, saçlar belirgin şekilde kısa olup yaşamları boyunca çocukların saçları hiç kesilmemişti. Tüm vücut kıllarında seyrelme, seyrek kaş, kirpik, pubik ve vücut kıllarının yok denecek kadar az olması, plantar bölgelerde hiperkeratoz ve ragadlar, sarımsı veya diskolore tırnaklar mevcuttu. Hastaların, burun kökünde basıkık, sivri burun, ince üst dudak ve geniş kulak kepçesi şeklinde atipik bir yüz görünümü mevcuttu. Konik veya silindirik şekilde seyrek dişler, hastaların her üçünün de ellerinde 3-4. parmaklarda, ayaklarında 2-3-4. parmaklarda proksimalde yapışıklık, geniş avuç içi ve kısa parmaklar mevcuttu (Resim 1, 2, 3). Aileden yazılı onay belgesi alınarak hastalar fotoğraflandı.

Yapılan laboratuvar incelemede tiroid fonksiyon testleri ve immünglobulin E'yi de içeren biyokimyasal değerlerde herhangi bir patoloji saptanmadı. Hastalarımızda tekrarlayan infeksiyon öyküsü yoktu ve immunolojik açıdan tetkikleri normaldi. Işitme testi ve IQ muayenesi normaldi. Her üç hastanın da göz muayenesinde hipermetropi, nörolojik değerlendirme sonunda ise optik disklerinin soluk ve tilted disk olduğu saptandı. Eklemlerde hiperfleksibilite ve yavaş konuşma tespit edildi. Hastaların el ve ayak radyografik incelenmesinde osseöz sindaktili saptandı. Kardiolojik değerlendirme ve abdominal USG normaldi.

Deri biopsi materyalinin histopatolojik incelemede kıl folikülleri ve sebase glandlarda sayıca azalma ve boyutlarında küçülme saptanarak ektodermal displazi ile uyumlu bulundu (Resim 4). Klinik ve histopatolojik değerlendirme sonucunda hastalara ailesel ektrodaktili ektodermal displazi-klefting sendromu tanısı konuldu.

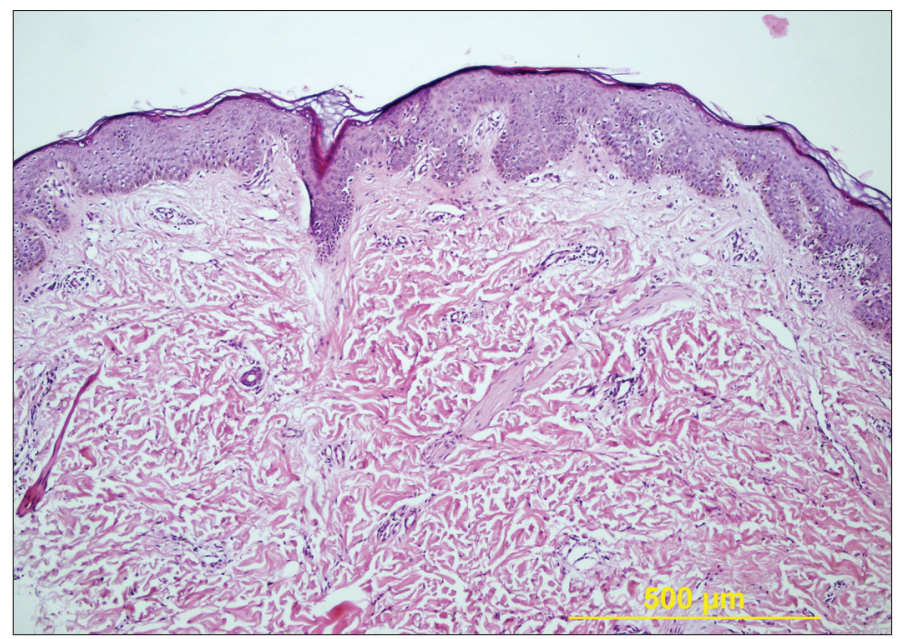

Resim 4. Dermada deri eklerinin (kıl folikülleri ve sebase glandlar) izlenmediği kesitte, fokal bir alanda lenfosit eksositozu görülmektedir (H\&E x100) 


\section{Tartışma}

Ektodermal displazi geniş, heterojen, kalıtımsal bir hastalık grubu olup saç, tırnak, diş ve ter bezlerini içeren ektodermal eklerden en az birinde, morfolojik gelişim boyunca gözlenen yapısal ve/veya fonksiyonel defekt ile karakterizedir1,2,3.

Ektodermal displazi sadece ektodermal yapıların eksikliği ile seyreden klasik tipin dışında vücuttaki diğer organlarında etkilendiği sendromlar şeklinde olabilir. Sendrom tipine sıklıkla sağırık, iskelet anomalileri, mental retardasyon, iktiyoz, palmoplantar keratoderma, göz anormallikleri, yüz deformiteleri, yarık damak-dudak ve diğer sistemik bulgular eşlik etmektedir2.

Literatürde bildirilen sindaktilinin eşlik ettiği ED sendromlarının birkaçının klinik özellikleri; Rook ve ark. tarafından bildirilen nadir bir ED tipinde, pili torti, diş anomalileri, tırnak displazisi, lordoz ve sindaktili mevcuttur. Baisch's sendromu ise diğer bir nadir ED sendromu olup diş anomalileri, anonişi, sinpolidaktili, gecikmiş kemik yaşı, normal saç ve ter bezleri ile karakterizedir?

Whiting sendromu, konjenital alopesi, diş anomalileri, ayrık diş ve sindaktili ile karakterizedir8. Boudghene-Stambouli ve Merad-Boudia hipotrikoz, diş anomalileri, parsiyel deri sindaktilisi, palmar keratoderma ve kuru deri gözlenen 5 etkilenmiş bireyin olduğu bir aile tanımlamışlardır9. Illyina ve ark.10 elin 3-4. ve ayağın 2-3. parmaklarında sindaktili, hafif düzeyde mental retardasyon, hipotrikoz, kuru deri, geniş palpebral aralık, geniş burun köprüsü, açık ağız, anormal kulaklar ve hafif hipohidroz ile karakterize ED sendromu tanımlamışlardır. Freihofer ve ark. ${ }^{11}$ nazal anomali, Lipson ve ark. ${ }^{12}$ iskelet ve kardiyak anomalileri ve sindaktilinin eşlik ettiği ED vakaları bildirmişlerdir.

Sindaktilinin eşlik ettiği diğer bir ED formu okülodentoosseöz displazi olup otozomal dominant veya otozomal resesif geçişli olabilir2,7. Bu form bilateral mikroftalmi, anormal küçük burun, hipotrikoz, diş anomalileri, 5. parmakta kampilodaktili, 4 ve 5. parmaklarda sindaktili, ayak parmaklarında kayıp ile karakterizedir2,7.

Tariq ve ark. ${ }^{7} 2009$ yılında ED sendrom bulgularından hipohidroz, hipoplastik tırnak, diş hipoplazisi, hiperhidroz, palmoplantar keratoderma ve bilateral parsiyel kutanöz sindaktili bulunan Pakistanlı bir aile tanımlamıştır. Bu bulguların bazıları daha önce ED-sindaktili sendromu (Boudghene-Stambouli ve Merad-Boudia'nın sunduğu) ve Baisch's sendromunda tanımlanmıştır. Fakat ince vücut kılları, sarımsı el ve ayak tırnakları, plantar keratoderma, hiperhidroz, kardiomegali, foliküler hiperkeratoz, sivri burun, ince üst dudak ve geniş kulak kepçesi gibi bazı bulguların ED-sindaktili sendromu ve Baisch's sendromunda bildirilmemesinden dolayı bu klinik tablo ektodermal displazi-kutanöz sindaktili (EDCS) şeklinde tanımlanmıştır?

Ektrodaktili Ektodermal displazi-klefting sendromu (EEC sendromu); ektodermal displazi bulguları yanında, yarık dudak ve/veya yarık damak, seyrek saçlı deri, malforme kepçe kulak, el ve ayak parmaklarında kısmi veya tam olan sindaktili ile seyreden, otozomal dominant geçişli bir ED sendromudur. Bu sendromda birkaç vakada hafif mental gerilik ve böbrek anomalisi rapor edilmiştir13,14. Ektrodaktili, ellerin ve ayakların orta kısmındaki parmakların füzyonundan yokluğuna kadar geniş bir yayılım gösteren defekt olarak tanımlanmaktadır. Dolayısıyla sindaktili tanımı da ektrodaktili tanımının içerisinde yer almaktadır13,14.

EEC sendromlu vakaların \%84'ünde ektrodaktili, \%77'sinde ektodermal displazi, \%68'inde yarık damak ve/veya dudak, \%59'unda lakrimal kanal anomalisi, \%23'ünde genitoüriner kanal anomalisi, \%14'ünde sağırlık ve \%7'sinde mental retardasyon bulunmaktadır. Sendromun major tanı kriterleri; ektodermal displazi, ektrodaktili, yarık damak ve/veya dudak, lakrimal kanal anomalisidir. Hastada başka bir sendromu işaret eden bir bulgu olmaması koşulu ile major tanı kriterlerinden en az ikisinin varlığı tanı koydurucudur. Sendromun tanı kriterlerine dikkat edilirse aslında yarık damak ve/veya dudak, lakrimal kanal anomalisi olmadan sadece ektodermal displazi ve ektrodaktili olan vakalar da tanı kriterlerini karşılamaktadır ${ }^{14}$. Bununla birlikte ektrodaktili tanımının sindaktiliyi de kapsayan geniş bir anlamı olması nedeniyle literatürde ayrıca EDsindaktili sendromu tanımlamasının olması anlam kargaşası yaratmaktadır. ED sendromunun saç, tırnak, diş, ter bezleri ve diğer organ tutulumlarını içeren 200'den fazla alt tipi veya genetik farklılığının tanımlanmış olması da bu karışıklığı artırmaktadır2.

Bizim olgularımızda saçların seyrek olması, zor uzaması, kolay dökülmesi, vücut kıllarında dökülme, diş problemleri (dişlerin geç çıkması, orta kesici dişlerin koni şeklinde oluşu), ince ve kuru deri, sivri burun, burun kökünde basıklık, ince üst dudak ve geniş kulak kepçesi olan atipik bir yüz görünümü, ellerinde 3-4. parmaklarda, ayaklarında 2-3-4. parmaklarda proksimalde yapışıkık geniş avuç içi ve kısa parmakların varlığı ile ektodermal displazi-kutanöz sindaktili sendromu tanısı konuldu. Ancak hastalarımız, yarık dudak ve/veya yarık damak bulunmamasına rağmen EEC sendromu tanı kriterlerini karşılamaktaydılar.

Ektodermal displazi sendromu sıklıkla $X$ resesif, nadiren otozomal resesif veya otozomal dominant geçişli olabilir. Etkilenen hastaların \%90'ı erkektir1-6. Oysa EEC sendromu otosomal dominant geçişlidir2. Bizim olgularımızın üç kız kardeşte gözlenmesi daha çok EEC sendromu ile uyumlu olduğunu düşündürdü.

Oftalmolojik muayenede saptanan tilted disk; daha çok konjenital anomalilere eşlik eden bir klinik bulgu olup, optik diskin uzun ekseninin oblik yerleşim gösterdiği bilateral, benin bir konjenital optik disk anomalisidir ${ }^{16}$. Yaptığımız literatür incelenmesinde ektodermal displazi sendromu ile tilted disk birlikteliğine rastlanmamış olup bizim olgularımız bu açıdan literatürdeki ilk olgulardır ${ }^{16}$.

Bu çocukların tedavisi yüksek ısıdan korunmak, suni gözyaşları, erken dental müdahele ve sindaktili açısından gerekli cerrahi müdaheleyi içerir. Ektrodaktili ektodermal displazi-klefting sendromu tanısı konulan bu ailesel olguları nadir gözlenmesi nedeniyle sunuyoruz.

\section{Kaynaklar}

1. Itin PH, Fistarol SK: Ectodermal dysplasias. Am J Med Genet C Semin Med Genet 2004;131:45-51

2. Visinoni $A F$, Lisboa-Costa $T$, Pagnan NAB, Chautard-Freire-Maia EA: Ectodermal Dysplasias: Clinical and Molecular Review. Am J Med Genet A 2009; 149A: 1980-2002.

3. Koç E, Arca E, Tunca M, ve ark: Genodermatozlar: Retrospektif Bir Çalışma. Türkderm 2006;40:133-5.

4. Anıl AB, Yücesoy I, Arslan G, Arıdaşır Ö, Aydoğan G: Ektodermal Displazi. Göztepe Tıp Dergisi 2003.18:126-8.

5. Talo T, Acun Kaya F: The Effects of Ectodermal Dysplasia on Periodontal Tissues. Journal of International Dental And Medical Research 2009;2:53-7.

6. Braun-Falco O, Plewing G, Wolff HH, Burgdorf WHC: Dermatology. 2nd ed. Berlin. Springer, 2000;1093-1094.

7. Tariq $\mathrm{M}$, Khan $\mathrm{MN}$, Ahmad $\mathrm{W}$ : Ectodermal dysplasia-cutaneous syndactyly syndrome maps to chromosome 7p21.1-p14.3. Hum Genet 2009;125:421-9.

8. Whiting DA: Structural abnormalities of the hair shaft. I Am Acad Dermatol 1987;16:1-25.

9. Boudghene-Stambouli O, Merad-Boudia A: Association of ectodermal dysplasia and syndactylia. Ann Dermatol Venereol 1991;118:107-10.

10. Ilyina HG, Amoashy DS, Grygory HA: "New" ectodermal dysplasia with mental retardation and syndactyly. Am J Med Genet 1995; 58:345-7.

11. Freihofer HP, Walji S, Brunner HG: Ectodermal dysplasia, cleft lip/palate, and severe cutaneous and osseous syndactyly in a mentallyretarded girl: A new multiple malformation syndrome. Am J Med Genet 1997;70:211-5.

12. Lipson M: Anew type of ectodermal dysplasia associated with skeletal and cardiac abnormalities. Am J Med Genet 1988;31:2.

13. Zlotogora J: Syndactyly, ectodermal dysplasia, and cleft lip/palate. J Med Genet 1994;31:957-9.

14. Buss PW, Hughes HE, Clarke A: Twenty-four cases of the EEC syndrome:clinical presentation and management. J Med Genet 1995;32:716-23

15. Ogur G, Yuksel M: Association of syndactyly, ectodermal dysplasia, and cleft lip and palate: report of two sibs from Turkey. J Med Genet 1988:25:37-40.

16. Arıcı K, Demircan S, Topaklara A, Güler C: 4 Kız Kardeşde Tilted Disk. RetinaVitreus 1997:5:54-7. 